\section{THE BIRTH OF MODERN BRITISH PLASTIC SURGERY}

The cover of this issue is based on a portrait taken of New Zealand-born ENT surgeon Harold Gillies (18821960) in about 1915 while he was working as a medical officer with the British Red Cross.

After studying at the University of Cambridge, Gillies moved to St Bartholomew's Hospital in London to complete his clinical training, specialising in otolaryngology. In 1915, Gillies left behind his hospital posts to work as a general surgeon with an ambulance unit on the Continent. While posted in France, Gillies was inspired by a number of European practitioners, namely French-American dentist

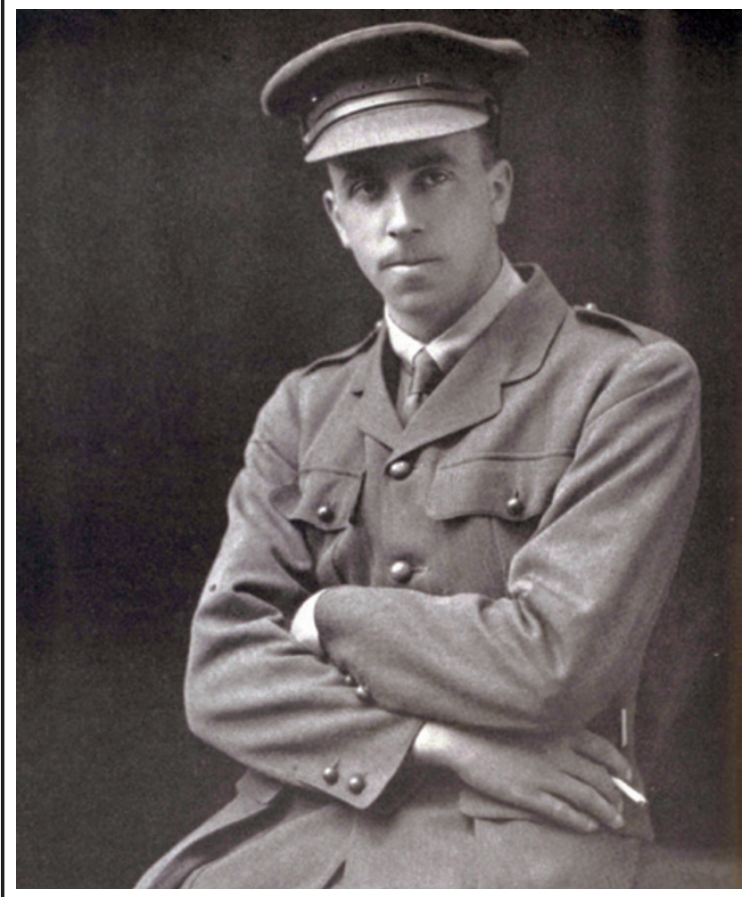

Portrait of Harold Gillies (1882-1960) as a medical officer, c.1915. Unknown source.
Charles Valadier (1873-1931) and Martinique-born surgeon Hippolyte Morestin (1869-1919).

Motivated by the reconstructive surgery he observed, Gillies lobbied the British authorities for a specialist unit. In January 1916, Gillies was posted to the Cambridge Military Hospital at Aldershot 'for special duty in connection to plastic surgery'.

Gillies and his colleagues at Aldershot were quickly overwhelmed with patients and by June 1917 plans were made for the unit to be relocated to larger premises at Frognal House in Sidcup. Formally opened in August 1917, the new Queen's Hospital was Britain's first dedicated plastic and jaw institution. It was arguably at this hospital that modern British plastic surgery was born. Guided by the belief that facial reconstructive surgery was an art, Gillies combined aesthetics and function when undertaking procedures. While publications from European surgeons were influential, Gillies and the team at Sidcup relied on their own creativity to treat the variety of traumatic disfigurements they received. Gillies favoured an interdisciplinary approach to facial injuries and worked closely with dental surgeons such as William Kelsey Fry, Leonard King and Alexander Fraser at Aldershot and Sidcup.

\title{
NEW CHARITY WILL EDUCATE ON DENTAL TRAUMA
}

A new charity is due to launch in November to help educate the public and dental professionals in the management of dental trauma.

Dental Trauma UK has been set up to help improve the care and treatment options for patients following traumatic dental injuries.

According to the charity, too many people are losing teeth unnecessarily after dental trauma, mainly because they are unaware of basic preventive steps to undertake in the aftermath of dental injury, such as re-implanting it, or putting it in milk and seeing a dentist urgently.

Miss Serpil Djemal, Consultant in Restorative Dentistry at King's College Hospital, London, and founder of Dental Trauma UK, said: 'More teeth can be saved if we can better educate the public about what to do in the immediate aftermath of dental trauma injury. We are really excited about getting started.'

Dental Trauma UK will work to raise awareness among the general public, but also those who are often 'first on the scene' when dental injury occurs - including teachers, youth workers, paramedics, police and sports coaches.

The charity will also collect research information on the number, causes and types of traumatic dental injuries throughout the UK as well as provide specialist support and advice to dental professionals to disseminate best practice in this area.

http://www.dentaltrauma.co.uk/

\section{HONOURS, AWARDS, APPOINTMENTS}

Excellence in dental education At the recent Association for Dental Education in Europe (ADEE) Annual Conference in Riga, Latvia, three UK-based academics were recognised with 'Excellence in Dental Education' Awards. Two awards were made in the 'Early Career' category (less than eight years' experience in dental education), of which one went to Mr Upen Patel (Birmingham). Three awards were made in the 'Mature (Senior)' category, of which one each went to Dr Undrell Moore (Newcastle), and Dr Chris Lynch (Cardiff). The aim of these awards is to provide international recognition of excellence in dental education to individuals who have not yet achieved the rank of 'Professor'. Further information is available from the ADEE website: www.adee.org

\section{Award hat trick}

British Dental Health Foundation President and Board Chair Dr Tony Newton received three awards in August from Durham University: his Doctorate in Business Administration (DBA), the Postgraduate Certificate in Academic Practice, and the prize for Best Doctoral Thesis for the Business School DBA Summer Congregation 2014. Dr Newton's research centres on what makes some people much more effective at networking than others, and whether training can have a lasting effect on improving those skills.

First academic core trainees Zehra Yonel and Jonathan Lewney have recently been appointed as the first Academic Dental Core Trainees (DCTs) in the UK. These innovative, two-year posts offer six month rotations in restorative dentistry and paediatric dentistry at Birmingham Dental Hospital, maxillofacial surgery at University Hospital Birmingham, and community dentistry within Birmingham Community Healthcare Trust. Each post offers up to $50 \%$ protected time for academic and research pursuits and aims to prepare DCTs for a clinical academic career. 